\section{A Influência da Denominação de Origem na Percepção de Consumidores de Café: Um Estudo com Brasileiros e Franceses}

\author{
Adriana Dossin, Fernanda Lazzari, Gabriel Sperandio Milan e \\ Tatiana Piccin
}

\section{RESUMO}

As indicações geográficas conferem autenticidade aos produtos, estimulando a economia local. Dentre elas, a Denominação de Origem (DO) é a única a garantir padronização dos métodos de produção, inferindo qualidade ao produto final. As DOs brasileiras são utilizadas em âmbito nacional, mas podem conferir vantagem competitiva em nível internacional. Assim, este estudo analisou a utilização do selo de DO em cafés da região do Cerrado Mineiro e seu efeito na percepção de qualidade, confiança, intenção de compra e disposição de preço a pagar de consumidores brasileiros e franceses. Para isso, foi realizada uma pesquisa experimental com design fatorial 3x2, considerando três modelos de embalagem para o café, com variação na apresentação do selo "Made in Brazil" e na DO. A amostra foi composta por 180 casos válidos, sendo 90 consumidores franceses e 90 brasileiros. Os resultados mostram que o reconhecimento da região certificada influencia as percepções sobre o produto, tanto para os consumidores brasileiros quanto para os consumidores franceses.

Palavras-Chave: comportamento do consumidor; avaliação de produtos; denominação de origem; efeito país de origem; estudo multicultural.

\section{The Influence of Denomination of Origin on The Perception of Coffee Consumers: A Study with Brazilians And the French}

\section{ABSTRACT}

Geographic indications of origin grant authenticity to their products, stimulating the local economy. In their variations, the Denomination of Origin $(D O)$ is the only one to provide standardization of production methods, conceding quality to the final product. Brazilian's DOs are used nationally; but they can be useful ininternational competitive advantage. Thus, the study analyzed the utilization of Denomination of Origin's certificate on coffees from Cerrado Mineiro's region and its effect on quality perception, reliability, purchase intention and the willingness of Brazilians and French consumers to pay for it. Hence, an experimental research with $3 \times 2$ factorial design was accomplished, considering three coffee package models, that only changed the presentation of "Made in Brazil" label and DO's certificate. The sample consisted of 180 valid cases, of which 90 were French consumers and 90 were Brazilian. The results show that the aknowledgment of a certificated region affects in its influence over the product, both for Brazilian consumers and for French consumers.

Keywords: consumer behavior; product evaluation; denomination of origin; country of origin effect; multicultural study.
Recebido em:16/09/2017

Aprovado em: 28/05/2018 Última Modificação: 11/10/2018

Check for updates

Adriana Dossin (1D,

Universidade de Caxias do Sul, Brasil. Graduada em Comércio Internacional,

Universidade de Caxias do Sul, Brasil.

adossin@ucs.br

Fernanda Lazzari iD, Programa de Pós-Graduação em Administração, Universidade de Caxias do Sul, Brasil.

Doutora em Administração,

Universidade Federal do Rio Grande do Sul, Brasil.

fernandalazzari@hotmail.com

Gabriel Sperandio

Milan (ID,

Programa de Pós-Graduação em

Administração, Universidade de Caxias do Sul, Brasil.

Doutor em Engenharia de Produção, Universidade Federal do Rio Grande do Sul, Brasil.

\section{gsmilan@ucs.br}

Tatiana Piccin (iD,

Universidade de Caxias do Sul, Brasil. Graduada em Comércio Internacional, Universidade de Caxias do Sul, Brasil.

piccintati@gmail.com 


\section{Introdução}

A imagem do país de origem pode conferir uma vantagem competitiva à empresa ou à(s) sua(s) marca(s) em mercados globais, atuando como parâmetro de qualidade do produto. Entretanto, a imagem percebida depende da categoria do produto que está sendo ofertado e do país no qual ele é produzido (Yeh, Chen, \& Sher, 2010). Assim sendo, é essencial que haja um alinhamento entre o produto e a reputação que o país de origem tem sobre o mesmo, a fim de evitar efeitos negativos na percepção do consumidor (Lampert \& Jaffe, 1998).

De acordo com Hanzaee e Khosrozadeh (2011), quando o efeito país de origem está sendo apresentado juntamente a outros fatores de relevância para o consumidor, o mesmo pode ser observado de duas formas: atuando como efeito "halo" ou resumindo todos os demais fatores. O efeito "halo" se apresenta quando o consumidor não é familiar aos produtos de um paísespecífico, e a imagem do país atua como uma espécie de "guia" que irá direcionar as expectativas do mesmo. Porém, quando o consumidor já possui experiências prévias com produtos de certa nacionalidade, os produtos conhecidos sumarizam a qualidade esperada para todos os demais, formando a imagem do país de origem.

No intuito de obter resultados mais consistentes, as pesquisas sobre o efeito país de origem na decisão de compra do consumidor vêm aprofundando seus estudos em locais com maior homogeneidade geográfica e sociocultural, tal qual estados, cidades e regiões. Surge, desta forma, o conceito de efeito da região de origem (Luceri, Latusi, \& Zerbini, 2016). Em um consenso geral, até o momento, os autores afirmam que o efeito região de origem confere maior valor aos produtos e assim é necessário reconhecer a importância das indicações geográficas e suas variações, como é o caso das Denominações de Origem (DOs) na valorização de produtos regionais típicos (Chamorro, Rubio, \& Miranda, 2015).

Visando atribuir reconhecimento e boa reputação aos produtos característicos de determinada localidade, o INPI - Instituto Nacional de Propriedade - concede aos produtores o registro de Indicação Geográfica, que avalia se os produtos apresentam qualidades únicas em função de recursos naturais, cultura, clima e habilidades de produção. Este registro apresenta duas modalidades: a Indicação de Procedência e a Denominação de Origem (DO), sendo esta última mais rígida com relação à qualidade e aos processos de produção (INPI, 2015).

Neste sentido, segundo dados da ONU - Organização das Nações Unidas do Brasil (ONU Brasil, 2015), o comércio de commodities representa aproximadamente 60\% das exportações do Brasil. Dentre estes produtos, encontra-se o café, do qual o Brasil é o maior produtor global e possui qualidade reconhecida internacionalmente. Estimativas do MAPA Ministério da Agricultura, Pecuária e Abastecimento (2016a) apontam que tanto a produção quanto as exportações de café terão crescimento de aproximadamente $25 \%$ na próxima década.

A primeira região brasileira produtora de café demarcada geograficamente é a área do Cerrado Mineiro, que, de acordo com dados 
do MAPA (2016b), é a única localidade produtora de café no Brasil a possuir o certificado de Denominação de Origem (DO), conhecido como "Região do Cerrado Mineiro". A região apresenta condições privilegiadas para o desenvolvimento de grãos de alta qualidade, com sabor distinto, possibilitando um diferencial competitivo (Calliari et al., 2007). Desta maneira, é possível afirmar que todo o café produzido nessa região é de alta qualidade e apresenta valor intrínseco único. De forma prática, a DO é apresentada através de um selo nas embalagens de café, garantindo as características do produto e transmitindo confiança ao consumidor. O selo foi conquistado no ano de 2014 por meio do INPI (2015) e a espécie oficial é o coffea arábica.

$\mathrm{Na}$ Europa, os consumidores têm um conhecimento bem mais difundido a respeito das indicações geográficas e, além de utilizarem a DO para garantir a qualidade, fazem questão de proteger seus produtos da competição global, patenteando os mesmos. Para tal, foi estabelecido em 1958 o Acordo de Lisboa para a Proteção de DO e seu Registro Internacional, no qual apenas 26 países fazem parte. É válido ressaltar que apenas doze integrantes possuem o certificado de Denominação de Origem Protegida e, dentre eles, 95\% são países europeus. A França se destaca com o maior número de PDOs (Protected Denomination of Origin), devido a seus queijos, vinhos e champanhes (Gurgel, 2005).

Consoante isso, o estudo aborda a utilização do selo de DO como forma de gerar vantagem competitiva para o café da Região do Cerrado Mineiro, tanto em âmbito nacional, quanto internacional. Para tanto, foi analisado o efeito país de origem Brasil e a influência do selo de DO sobre a qualidade percebida, a confiança, a intenção de compra e a disposição de preço a pagar de consumidores brasileiros e franceses de café, além de serem estabelecidos comparativos entre os efeitos observados nos dois públicos da pesquisa. A operacionalização do estudo deu-se de forma virtual, por meio de um experimento com design fatorial 3x2 (sem informação sobre origem; apenas selo "Made in Brazil"; selo "Made in Brazil" e selo de DO do Cerrado Mineiro x Brasileiros; Franceses), com um total de 180 indivíduos.

Buscando enriquecer os estudos sobre o efeito país de origem, o presente trabalho encontrou no selo de DO um modo de agregar ao produto as propriedades do local de procedência e do selo de garantia de qualidade. Além disso, este estudo agrega compreensão do potencial dos produtos tradicionais do Brasil no mercado internacional, assim como evidencia a oportunidade de explorar o selo de DO como uma possível vantagem competitiva em nível global, além do uso doméstico, ou seja, no mercado nacional.

Além disso, o estudo se mostra relevante aos produtores de café da Região do Cerrado Mineiro ou aos gestores ligados ao setor, permitindo a eles um maior conhecimento a respeito dos fatores que induzem a compra de um café ou outro entre seus concorrentes e do real efeito da DO na percepção do público. Ainda que com menor detalhamento, agrega também conhecimento ao produtor brasileiro que apresenta em seus produtos o selo de DO às instituições governamentais controladoras do registro. 


\section{Quadro Teórico-Empírico}

Ao apresentar o quadro teórico, necessário à fundamentação do presente estudo, foram abordados o efeito país de origem no contexto do Brasil, o efeito país de origem e a percepção do consumidor e a Relevância da Denominação de Origem (DO) para a avaliação de produtos.

\section{O Efeito País de Origem do Brasil}

Além dos consumidores comprarem produtos com base na marca ou no bom desempenho, o país de origem é considerado na decisão de compra (Maheswaran, 2006). Ademais, Biehal e Sheinin (1998) afirmam que a imagem do país de origem deveria ser trabalhada pela empresa de maneira semelhante às marcas: através de propaganda e embalagem. Em acréscimo, Lampert e Jaffe (1998) afirmam que quando esta imagem for positiva, pode ser utilizada como um recurso à promoção do item e quando for negativa, sua divulgação deve ser evitada ao máximo, pois poderá conferir depreciação ao mesmo.

O estudo desenvolvido por Almeida e Drouvot (2009) constatou que tanto os consumidores brasileiros quanto os franceses avaliam os produtos de origem brasileira no que tange à qualidade como significantemente inferiores aos produzidos em países desenvolvidos. Ainda, ao questionarem a respeito dos setores econômicos nos quais o Brasil apresenta destaque, os autores obtiveram a menção de dois setores: vestuário (moda praia) e agroindústria (café, frutas, carne e cachaça). No estudo de Souza, Streblau, Silva e Streblau (2014), foi percebido que os produtos brasileiros obtiveram melhor avaliação dentre os países próximos geograficamente do que países europeus, por exemplo.

Giraldi, Ikeda e Carvalho (2008) investigaram a relação de estudantes holandeses com produtos brasileiros por meio da abordagem de quatro classes de itens: carne bovina, frutas frescas, móveis e calçados. Dentre eles, os calçados foram os mais avaliados negativamente, enquanto as frutas frescas apresentaram o maior percentual de atitudes favoráveis. Os autores notaram que os respondentes que avaliaram os calçados de forma positiva foram aqueles que conheciam o produto, demonstrando, assim, que uma das dificuldades do Brasil em relação a sua imagem se encontra em tornar seus produtos conhecidos no mercado.

Os estudos realizados por autores estrangeiros sobre o efeito país de origem Brasil, como Nebenzahl e Jaffe (1996) e Anholt (2007), trouxeram evidências empíricas e inferências importantes para as empresas brasileiras que têm interesse em internacionalizar seus produtos, constatando de forma unânime a informação de que a imagem brasileira não está associada à alta qualidade de produtos tecnológicos (Giraldi \& Carvalho, 2004). Já Nebenzahl e Jaffe (1996) evidenciaram que, como a imagem de um país influencia as expectativas dos consumidores com relação a produtos, o consumidor global espera pagar menos por produtos brasileiros. Anholt (2007), por sua vez, estudou a imagem de 35 países e constatou que a "marca Brasil" não é muito utilizada para promover as exportações do país, sendo que nos casos quando isto ocorre, o consumidor não é atraído, pois há pouco conhecimento 
do Brasil no mercado internacional. Sendo assim, de acordo com Guina e Giraldi (2013), o Brasil possui uma imagem que no geral é positiva, mas que, no entanto, é pouco produtiva e pouco explorada pelo país. Souza et al. (2014) indicam que os produtos brasileiros não têm divulgação satisfatória em sete dos dez países em que a pesquisa foi realizada.

Ainda que se sejam observadas semelhanças no perfil comportamental dos consumidores, é difícil que ocorra uma unanimidade com relação à imagem de um país, uma vez que a formação da imagem dos indivíduos em relação a um país pode ocorrer de diversas formas e sofrer inúmeras influências. Observa-se, ainda, que o "Made in Brazil" pode conferir imagem favorável para algumas categorias de produtos, inclusive sendo utilizado como fonte de vantagem competitiva em setores de mercado específicos, que podem se apropriar da geografia, cultura e musicalidade do Brasil, a fim de promover seus produtos e marcas no exterior. Nesses casos, conforme Sutter, Polo e Maclennan (2014), a imagem do país de origem deve ser explorada pelas empresas brasileiras, porém utilizada juntamente com outras vantagens competitivas, para que os produtos não se tornem caricatos. Dessa forma, produtos que englobam a cultura e a regionalidade brasileira devem utilizar a imagem do país como uma das possíveis formas de conferir alguma vantagem competitiva, assim como produtos de cunho agropecuário, também propícios a esse contexto.

\section{O Efeito País de Origem e a Percepção do Consumidor}

O efeito país de origem é uma informação extrínseca à mercadoria, um atributo intangível e extrínseco do produto, que se distingue das suas características físicas (Mehmet, Pirtini, \& Erdem, 2010), assim como a qualidade e a imagem da marca (Maheswaran, 1994). Sobre a qualidade percebida, Steenkamp (1990) afirma que esta não se encontra na aquisição do item em si, mas no que os consumidores esperam que o produto vá lhes conferir. A significância do efeito país de origem na percepção do consumidor em relação à qualidade e também credibilidade do produto é confirmada pelos estudos de Chéron e Propeck (1997) e Kabadayi e Lerman (2011). Complementando, Andéhn e Decosta (2016) afirmam a influência existente na força de associação da marca ao país na avaliação dos consumidores, ou seja, o vínculo que o consumidor enxerga entre a marca e o país influencia na avaliação do produto.

Nesta direção, Ahmed e D'Astous (2002) verificaram que consumidores mais jovens, com nível de instrução e poder de compra superiores, avaliavam produtos estrangeiros de forma mais favorável que os demais. Por sua vez, Inglehart e Baker (2000) associaram estas variáveis a um aumento na confiança com relação a produtos de nações estrangeiras. Jiménez e San Martín (2010) corroboram a ideia concluindo que o efeito país de origem atua como provedor de confiança nos produtos, possibilitando a utilização de tal imagem por parte das empresas. Akdeniz Ar e Kara (2014) evidenciam que há uma associação positiva entre o estereótipo do país de origem de uma marca e a confiança do cliente na marca, sendo que países com melhor estereótipo geram uma confiança na marca maior. Além disso, Nijssen e 
Herk (2009) observam que a relação entre a satisfação do consumidor e a confiança é comprovadamente realçada pela percepção favorável do efeito país de origem.

Um país com forte imagem positiva, portanto, pode aumentar consideravelmente a percepção de qualidade de seus produtos e, consequentemente, a sua intenção de compra (Manrai \& Manrai, 1993). Clipa, Danilet e Clipa (2017) confirmam a relação entre país de origem e percepção de qualidade no seu estudo com consumidores romenos. Prendergast, Tsang e Chan (2010) abordaram em seu estudo a relação entre o grau de envolvimento e a intenção de compra frente a produtos importados. Para produtos que exigem alto grau de envolvimento, os consumidores apresentam maior aversão ao risco e optam por avaliarem suas escolhas através de atributos concretos. Para produtos que exigem menor envolvimento, o consumidor sente-se mais confortável em basear-se em fatores extrínsecos secundários para tomar suas decisões, dentre eles, o efeito país de origem da marca. Da mesma forma, Dobrenova, Grabner-Krauter e Terlutter (2015) também encontraram ligação entre país de origem e intenção de compra.

Outro fator que pode ser influenciado pelo efeito país de origem e gera vantagem competitiva para o exportador é a disposição de preço a pagar pelo consumidor para adquirir determinado produto. Conforme Ha-Brookshire e Yoon (2012), quanto mais os consumidores são expostos a notícias negativas sobre o país de origem dos produtos, mais tem-se um efeito país de origem negativo e menos eles estariam dispostos a pagar pelos produtos daquele país. Esse, segundo Johansson (1989), é o motivo de muitas empresas não se mudarem para países com custos de produção mais baixos, pois isso reduz o valor percebido em relação ao produto, impossibilitando a aplicação de preços de venda mais altos. Dessa forma, a informação do país de origem com imagem positiva conferirá vantagem competitiva ao produto, permitindo adoção de preços premium (Johansson \& Nebenzahl, 1986), uma vez que o preço de um produto no mercado não está diretamente associado aos seus custos de fabricação, mas ao preço que os consumidores estão dispostos a pagar (Bhakar, Bhakar, \& Dubey, 2015).

Vale destacar que o conhecimento do consumidor internacional ainda é vago e tendencioso em relação ao nível de qualidade da produção brasileira, de modo que se desconhecem aspectos relacionados à qualidade e aprimoramento tecnológico do parque industrial brasileiro (Fonseca, 2003 como citado em Giraldi \& Carvalho, 2004). Da mesma forma, a pesquisa de Rambalducci, Rambalducci, Feitosa e Feitosa (2008) mostrou que norte-americanos consideram que a divulgação do produto brasileiro é fraca ou nula e que produtos com o selo "Made in Brazil" são produtos baratos e com baixa qualidade.

De forma geral, a imagem do Brasil no exterioré, principalmente, associada a características esportivas (futebol) e características criativas (música e carnaval). Desta maneira, o Brasil não possui atribuições significativas ou relevantes quando se trata em prover bens de maior capacidade tecnológica ou de qualidade reconhecida pelo mercado externo. Esta percepção do consumidor internacional sobre o Brasil e, consequentemente, sobre os 
produtos brasileiros, está relacionada à pouca exposição dos produtos Made in Brazil ao consumidor estrangeiro e à veiculação do país em meios de comunicação internacionais que ressaltam apenas os aspectos negativos do país (Fonseca, 2003 como citado em Giraldi \& Carvalho, 2004). Sendo assim, para que as empresas brasileiras desenvolvam seus planos estratégicos no exterior de forma satisfatória, elas deveriam adotar estratégias que minimizem o efeito negativo da imagem do país ou buscar de criar possíveis fontes de vantagem competitiva.

\section{A Relevância da Denominação de Origem (DO) para a Avaliação de Produtos}

De acordo com a Lei Brasileira da Propriedade Industrial (LPI), lei 9.279, de 14/05/1996, há duas categorias de Indicação Geográfica: a Indicação de Procedência e a Denominação de Origem (DO). Para tanto, a proteção das indicações geográficas apresenta caráter estratégico ao Brasil, pois é um país que apresenta grande variedade de territórios, tanto em nível geográfico quanto etnológico, permitindo que muitos produtos com identidade própria sejam produzidos e comercializados mundialmente (Calliari et al., 2007). A Indicação de Procedência diz respeito ao território do produto, seja ele extenso como um país ou específico, que tenha se tornado conhecido como centro de extração, produção ou modo de preparo de algum produto. Já a DO, além das especificidades conferidas à indicação de procedência, refere-se também à matéria-prima utilizada, que deve ser própria do território de produção e do processo de fabricação do item, sendo necessário seguir a tradição local.

A utilização do selo de DO vem de encontro ao movimento da economia de escala e dos alimentos industrializados, uma vez que a DO determina a técnica utilizada dentre os produtores para garantir a qualidade do produto, exigindo que se mantenham fiéis à tradição local. Dessa forma, o processo de inovação torna-se mais lento, dificultando que produtos com DO consigam ser produzidos em grande escala (Kohls, Anjos, \& Caldas, 2016). A respeito do cultivo das tradições, Kuznesof, Tregear e Moxey (1997), ao questionar cidadãos britânicos a respeito do que era comida regional para eles, descobriram que, ao contrário de seus pais, os jovens consumidores não associam a comida regional apenas à feita nas diferentes regiões da Inglaterra, pois, devido à abertura do país para novas culturas, é possível experimentar a regionalidade com produtos estrangeiros.

Vale destacar que os europeus apresentam um conhecimento bastante difundido a respeito das indicações geográficas, devido ao Acordo de Lisboa para a Proteção de Denominação de Origem e seu Registro Internacional (Gurgel, 2005). Conforme Fotopoulos e Krystallis (2003), o uso do selo de Denominação de Origem Protegida (PDO) em produtos alimentícios tornou-se uma estratégia de marketing tão importante para as empresas do ramo quanto o gerenciamento da marca, no qual a sua informação confere originalidade e autenticidade aos produtos. Dado que o Brasil não integra o Acordo de Lisboa, o mais complexo certificado emitido pelo país é o da DO. 
É válido ressaltar que o fato da DO ser nacional não diminui a sua importância ou restringe a sua atuação apenas ao mercado doméstico, visto que não existe um acordo internacional para tal (Gurgel, 2005). Para Gómez e Molina (2012), a atuação da DO para alimentos e bebidas pode ser comparada à imagem de uma marca, no sentido que, quando uma marca é favorável, ela é capaz de repassar sua reputação a todos os seus produtos.

Neste horizonte, Verbeke e Roosen (2009) detectaram que o nível de atenção que o consumidor confere a rótulos de qualidade durante o processo de compra de alimentos é substancialmente superior ao conferido a indicações do país de origem. Isso mostra que, para muitos casos, a imagem negativa de um país pode ser enfraquecida na presença de selos de qualidade, os quais atuam como agentes moderadores do efeito país de origem. Entretanto, os autores identificaram que os selos de indicações geográficas, especificamente em produtos alimentícios, apresentam grande valor ao consumidor final, pois eles sinalizam as particularidades do produto e o nível de qualidade do mesmo, uma vez que o item não necessita ser de qualidade premium para o consumidor valorizar a informação.

O uso destes selos para conferir qualidade ao produto também é comprovado, pois a indicação geográfica é aplicada em bens de consumo não duráveis. Desse modo, por mais que eles apresentem preços mais elevados, exigem menor envolvimento por parte do consumidor. Dessa forma, visando acelerar suas decisões de compra, os consumidores acabam por fazer uso de dicas contidas nos rótulos para formarem sua opinião a respeito da qualidade do produto (Verbeke \& Ward, 2006). Em uma pesquisa feita com consumidores canadenses, azeites de oliva extra virgem que possuíam o selo de DO foram melhor avaliados do que aqueles que possuíam o selo de Indicação Geográfica. Contudo, essa diferença na percepção de qualidade foi muito mais expressiva quando comparada a produtos sem certificação alguma (Menapace, Colson, Grebitus, \& Facendola, 2011).

Ao optar por produtos de determinada região que apresentem o selo de DO, o consumo não se dá apenas por questões afetivas, mas também pela confiança nos processos de produção e padrão de qualidade (Calliari et al., 2007). Sendo assim, certificados de qualidade, como o selo de DO, garantem ao consumidor que o produtor adotou as técnicas e métodos exigidos para que se tenha alta qualidade, aumentando a credibilidade do produto perante consumidores e distribuidores (atacadistas ou varejistas) (Fotopoulos \& Krystallis, 2003).

A regionalidade dos produtos se tornou um importante critério na avaliação de produtos e decisão de compra (Lorenz, Hartmann, \& Simons, 2015). Da mesma forma que o efeito país de origem, os selos de DO também passam por três processos avaliativos do consumidor: o cognitivo, o afetivo e o normativo. Para tanto, o aspecto cognitivo se mantém com o uso racional dos aspectos externos, contidos na DO, a fim de deduzir a qualidade do produto (Hauser, Jonas, \& Riemann, 2011). Os aspectos afetivos também afetam na intenção de compra uma vez que a simpatia à determinada região é transferida ao produto e, indiretamente, pode se sobrepor a qualquer outro atributo (Obermiller \& Spangenberg, 1989). Contudo, o terceiro aspecto, o normativo, é reforçado por alguns estudos baseados no etnocentrismo, que afirmam que o consumidor dará preferência aos produtos da sua terra. 
Sua explicação encontra-se na proteção da própria cultura ou no simples sentimento de superioridade e preconceito às demais tradições (Fernández-Ferrín \& Bande-Vilela, 2013).

Luceri, Latusi, \& Zerbini (2016) realizaram um estudo com 600 estudantes do norte da Itália, analisando o efeito dos selos de certificação geográfica em maçãs com relação à intenção de compra e percepção da atitude da marca (brand atitude). A pesquisa mostrou que para ambas variáveis observadas, os produtos com selo de Indicação Geográfica ou com selo de DO apresentaram avaliações significantemente maiores. O estudo demonstrou também que os consumidores enxergam produtos com certificação de DO como produtos típicos, independente da conexão queos mesmos tenham com a região. Um outro estudo, com 427 consumidores de vinho de uma determinada região da Espanha, obteve resultados que foram ao encontro com a literatura, mostrando que há uma relação direta entre a imagem de uma região e a percepção de compra para com seus produtos. Além disso, foi evidenciado o fato de a região ser conhecida por produzir vinhos, o que aumentou a intenção de compra e assim, indiretamente, verificou-se uma maior percepção de qualidade por parte do consumidor (García-Gallego, Chamorro-Mera, \& García-Galán, 2015).

Como o mercado internacional está constantemente aumentando a demanda por produtos diferenciados, o setor agropecuário encontrou no selo de DO uma oportunidade de conferir diferenciação ao produto, já que investimentos nesse aspecto vem aumentando faturamento e, consequentemente, o lucro das empresas (Oberthuret al., 2011). Em convergência a isso, Verbeke e Roosen (2009) afirmam que uma grande parcela dos consumidores europeus está disposta a pagar preços premium por produtos típicos de alguma região específica. Isso é corroborado no estudo de Aprile, Caputo e Nayga (2012), que mostrou que, com relação ao mesmo produto, os consumidores pagariam primeiramente um maior preço premium aos produtos que apresentavam o selo de DO e, em segundo lugar, aos produtos com selo orgânico (Aprile, Caputo, \& Nayga, 2012).

\section{Método de Pesquisa}

O método de pesquisa adotado para o presente estudo se caracteriza como uma pesquisa quantitativa, a qualproporciona respostas que podem ser consideradas conclusivas (Malhotra, 2012). Ainda dentro do método quantitativo, foi optado pelo método experimental, no qual o pesquisador manipula uma ou mais variáveis independentes e observa os efeitos causados sobre as variáveis dependentes, ao mesmo tempo em que controla as variáveis externas (Remler \& Van Ryzin, 2011; Kirk, 2013). Para tanto, foi utilizada a abordagem entre sujeitos (between subjects), por meio da qual é possível analisar as diferenças entre os grupos de participantes do experimento, tendo em vista que cada indivíduo participou de apenas um dos cenários manipulados (Shadish, Campbell, \& Cook, 2001; Malhotra, 2012). Especificamente para a configuração dos grupos, foi empregado umdesign fatorial 3x2, considerando três modelos de embalagem para o produto (café), com variação na apresentação do selo "Made in Brazil" e na DO. 
As variáveis independentes consideradas foram o selo "made in" e o selo de DO. Já as variáveis dependentes foram os construtos qualidade e confiança percebidas, intenção de compra e disposição de preço a pagar. Desta forma, foi possível analisar a existência de correlação entre os selos e os fatores dependentes escolhidos. A fim de estudar os efeitos dos selos "Made in Brazil" e de DO da "Região do Cerrado Mineiro" na percepção dos consumidores, foi criada uma marca ("Morro Alto"), bem como foram desenvolvidas embalagens de café. Foram elaboradas três versões de embalagem: uma utilizando apenas a marca fictícia, outra com a marca fictícia adicionada ao selo "Made in Brazil" e outra com a marca fictícia adicionada ao selo "Made in Brazil" e ao selo de DO "Região do Cerrado Mineiro". Todas informavam a mesma composição do produto: $250 \mathrm{~g}$ de café torrado e moído e 100\% tipo arábica, conforme exigências da Federação dos Cafeicultores do Cerrado (2015). Elaborou-se, então, uma variedade de seis embalagens, devido às manipulações pretendidas no estudo e às traduções necessárias para atingir consumidores no Brasil e na França (um exemplo dessas embalagens pode ser observado no Apêndice A). Dessa forma, então, foram elaboradas seis diferentes versões do instrumento de coleta, nas quais constava uma imagem da embalagem, as perguntas de checagem e de perfil, bem como as questões relacionadas aos construtos avaliados.

O questionário foi dividido em três seções. A primeira seção foi composta por oito perguntas sobre o perfil do respondente, com destaque para a pergunta sobre o hábito de beber café, que foi determinante para validar a participação do mesmo na pesquisa. Em seguida, na segunda e terceira seções, o respondente foi exposto à imagem da embalagem e instruído a responder as questões seguintes, baseando-se unicamente nas informações contidas na imagem da embalagem que ele havia visualizado.

Assim, após o respondente analisar a imagem da embalagem, fez-se algumas perguntas para checagem da manipulação. Todas as perguntas de checagem possuíam caráter determinante para validação da participação do respondente no estudo. Por fim, havia as questões para avaliação dos construtos, que foram respondidas de acordo com uma escala do tipo Likert de 7 pontos. Para análise do construto qualidade percebida, adaptou-se a escala proposta por Sweeney e Soutar (2001). Composta por seis questões, a escala possui coeficiente alfa de Cronbach de 0,95. Para avaliar confiança utilizou-se a escala proposta por Chaudhuri e Holbrook (2001), cujas quatro questões apresentaram alfa de 0,81. Com relação à intenção de compra, adotou-se a escala de Baker e Churchill Jr. (1977), composta por quatro questões e cuja confiabilidade foi de 0,71.Para avaliação da disposição de preço a pagar fez-se uma pergunta aberta, questionando quanto o respondente pagaria pelo produto apresentado na imagem. As questões utilizadas para avaliar os construtos estão disponíveis no Apêndice B.

Para a avaliação da disposição de preço a pagar, diferentemente dos outros três quesitos, não se fez uso de uma escala. Para tal, foi realizada uma breve pesquisa em supermercados na França e no Brasil, revelando o preço médio de produtos semelhantes ao anunciado na embalagem do estudo. Após informar o valor médio praticado no varejo destas duas cidades, a questão solicitava ao respondente qual o valor que o mesmo estaria disposto a pagar pelo café apresentado na imagem. 
Depois da realização do pré-teste, que não revelou necessidade de mudanças no instrumento de pesquisa, deu-se início ao processo de coleta de dados em ambos os países (Brasil e França), com um total de 180 participantes, 90 deles franceses e 90 brasileiros, selecionados por conveniência. No que diz respeito à coleta dos dados, foi desenvolvido um questionário em formato digital no Google Forms. O convite para participar da pesquisa, bem como o envio do link para respondê-la foi feito por meio de redes sociais como o Facebook e o Interpals. Os dados foram tabulados em um banco de dados e passaram por um tratamento inicial, momento em que foram desconsideradas as participações de todos aqueles que não possuíam a nacionalidade solicitada para seu grupo ou que declaravam não possuir o hábito de tomar café.

Após isso, por meio do cálculo do score padrão (Z), buscou-se identificar a existência de observações atípicas ou outliers. Neste estudo, nenhum dado foi retirado da base de dados, uma vez que não houve incidência de valores de Z superiores a 3 ou inferiores a -3. Na sequência, foi confirmada a normalidade dos dados por meio dos valores de assimetria e curtose e do teste de Kolmogorov-Smirnov (K-S). A verificação das variâncias deu-se através do teste de Levene, que indicou a homoscedasticidade dos dados. Na sequência, procedeu-se a uma análise descritiva dos dados, com análises das médias e das frequências das respostas.

Com base neste processo, analisou-se o perfil dos respondentes e as diferenças entre as médias dos construtos, para os grupos experimentais previamente definidos. Em seguida, para verificar se as diferenças encontradas eram estatisticamente significantes, foi empregada a análise de variância (ANOVA), considerando-se as recomendações encontradas na literatura (Tabachnick \& Fidell, 2012; Meyers, Gamst, \& Guarino, 2013; Warner, 2013), com teste post hoc de Tukey HSD (honestly significant difference), que têm por finalidade localizar e mensurar diferenças entre grupos, sendo que tal teste inicia com o cálculo da diferença mínima que deve haver entre duas médias com um nível de significância de 5\% (Hair Jr., Black, Babin, \& Anderson, 2010).

A validade interna pode ser incrementada pelo nível de controle que se tem em um experimento e, sendo assim, quanto mais controle, maior a certeza de que alterações na variável dependente são geradas pelas alterações nas variáveis independentes. Neste estudo, a fim de estabelecer a checagem da manipulação, que também busca expressar a validade interna do experimento (Khan, 2011), todos os respondentes foram questionados quanto ao produto relacionado à embalagem apresentada na imagem (questão de checagem inicial). Além disso, os respondentes cuja embalagem apresentava país de origem foram questionados sobre a origem do produto. Por fim, os participantes que visualizaram a embalagem com país e selo de DO adicionalmente foram submetidos a uma questão que verificava se o selo havia sido observado pelo respondente. Os respondentes que não responderam essas questões de forma correta foram automaticamente excluídos da amostra.

Por fim, vale destacar que, em relação à generalização dos resultados Shadish, Campbell e Cook (2001) afirmam que a validade externa pode ser 
aumentada quando um experimento demonstra o fenômeno em uma ampla variedade de condições. No caso desta pesquisa, a generalização seria possível através da replicação do estudo com a utilização de outros produtos em que possa ser avaliado o seu desempenho. No entanto, este estudo não realizou experimentos com outros produtos e não foram testadas condições diferentes de manipulação de variáveis daquelas já relatadas.

\section{Apresentação dos Resultados}

\section{Perfil dos Participantes}

Foram coletados 247 casos (questionários respondidos), sendo desconsiderados todos os respondentes que indicaram não ter hábito de consumir café. Dessa forma, foram considerados 180 questionários (ou casos) válidos, 90 deles respondidos por franceses e 90 por brasileiros. Os respondentes foram divididos em seis grupos, três grupos contendo respondentes franceses e três grupos formados por brasileiros (Figura 1).

Analisando o perfil dos participantes da pesquisa, 93 (ou 51,6\%) deles são do sexo masculino e 87 (ou 48,4\%) do sexo feminino, sendo que a idade média dos mesmos é de 28 anos. Em relação ao grau de escolaridade dos participantes, todos possuem o ensino médio completo e ingressaram ou concluíram o ensino superior.

\begin{tabular}{cclc}
\hline $\begin{array}{c}\text { Grupos } \\
\text { Experimentais }\end{array}$ & $\begin{array}{c}\text { Nacionalidade dos } \\
\text { Participantes }\end{array}$ & \multicolumn{1}{c}{ Embalagens Visualizadas } & $\begin{array}{c}\text { Casos } \\
\text { Válidos }\end{array}$ \\
\hline G1 & Francesa & Apenas com a marca & 30 \\
G2 & Francesa & Com a marca e o selo "Made in Brazil" & 30 \\
G3 & Francesa & Com a marca, o selo "Made in Brazil" e o selo de D0 & 30 \\
G4 & Brasileira & Apenas com a marca & 30 \\
G5 & Brasileira & Com a marca e o selo "Made in Brazil" & 30 \\
G6 & Brasileira & Com a marca, o selo "Made in Brazil" e o selo de D0 & 30 \\
\hline
\end{tabular}

Figura 1: Distribuição dos participantes

Nota: D0 = Denominação de Origem.

Fonte: Elaborada pelos autores.

Salienta-se que foi realizada a ANOVA e que foi constatado que os grupos do estudo experimental implementados não apresentam diferenças significantes no que se refere aos critérios analisados, mostrando-se homogêneos com relação à idade, ao nível de instrução.

Outro aspecto analisado no perfil dos respondentes foi em relação ao hábito dos mesmos em beber café. Mais da metade dos participantes (102 ou $56,7 \%$ deles) afirmou consumir ao menos uma vez ao dia a bebida. Os brasileiros, por sua vez, apresentaram-se mais assíduos na ingestão da mesma, sendo que 63 deles (ou 70\%) informaram consumir a bebida todos os dias e apenas 7 deles (ou 7,8\%) declararam beber café no máximo três vezes por semana. Já os franceses possuem um consumo mais moderado, 
pois 27 deles (ou 30\%) ingerem a bebida até três vezes por semana, enquanto que outros 39 (ou 43,3\%) bebem café todos os dias.

Ainda em relação à frequência de consumo, brasileiros consomem café, em média, 6,25 vezes por semana, enquanto franceses o fazem 5,1 vezes. O teste-t mostrou que a diferença de médias entre os grupos de brasileiros e franceses é significante $(p=0,000)$. No entanto, considerando apenas os grupos de respondentes brasileiros, não se observou diferença significante entre eles, já que a ANOVA apresentou um valor de $p=0,414$. Da mesma forma, os três grupos de respondentes franceses não mostraram diferenças significantes entre si neste aspecto $(p=0,910)$.

\section{Análise Descritiva e Paramétrica}

A Tabela 1 indica as médias obtidas em cada construto analisado, com exceção da disposição do preço a pagar, a qual foi analisada separadamente. Dentre os grupos de respondentes, o grupo G6 foi o que obteve as maiores médias nos três construtos analisados. Já as piores médias são apresentadas pelo grupo G1, formado por franceses, que visualizaram a embalagem sem adição de nenhum selo.

Tabela 1: Média para os construtos nos grupos experimentais

\begin{tabular}{|c|c|c|c|c|c|c|c|}
\hline & \multirow[t]{3}{*}{$\begin{array}{c}\text { Amostra } \\
\text { Completa }\end{array}$} & \multicolumn{3}{|c|}{ Brasil } & \multicolumn{3}{|c|}{ França } \\
\hline & & G1 & G2 & G3 & G4 & G5 & G6 \\
\hline & & Marca & $\begin{array}{c}\text { Marca + } \\
\text { Brasil } \\
\end{array}$ & $\begin{array}{c}\text { Marca + } \\
\text { Brasil + D0 } \\
\end{array}$ & Marca & $\begin{array}{c}\text { Marca }+ \\
\text { Brasil } \\
\end{array}$ & $\begin{array}{c}\text { Marca + } \\
\text { Brasil + D0 }\end{array}$ \\
\hline Qualidade percebida & 5,08 & 4,64 & 5,07 & 5,12 & 5,11 & 4,9 & 5,65 \\
\hline Confiança percebida & 5,11 & 4,59 & 5,16 & 5,44 & 5,01 & 4,83 & 5,61 \\
\hline Intenção de compra & 4,54 & 3,85 & 4,59 & 4,52 & 4,62 & 4,41 & 5,25 \\
\hline Disposiçãode preço a pagar & $\begin{array}{c}€ 4,90(f) \\
R \$ 10,24(b)\end{array}$ & $€ 4,39$ & $€ 5,21$ & $€ 5,09$ & $R \$ 10,08$ & $R \$ 10,06$ & $\mathrm{R} \$ 10,59$ \\
\hline
\end{tabular}

Nota: DO = Denominação de Origem.

Fonte: Elaborada pelos autores.

O construto "qualidade percebida" obteve a média geral de 5,08. É interessante observar que a média geral obtida para este construto entre os grupos G2 e G3, ambos formados por franceses, foi bastante próxima (5,07 e 5,12), sendo que o primeiro grupo visualizou a embalagem com apenas o selo "Made in Brazil" e o segundo com a embalagem também com o selo de DO. Em contraponto, entre os brasileiros, o café que continha a marca e a informação do país de origem obteve a pior média e o que possuía o selo de DO, a maior.

As médias obtidas foram submetidas à ANOVA e verificou-se que entre os franceses há diferença significante entre as avaliações de qualidade realizadas pelos grupos $\mathrm{G} 1$ e $\mathrm{G} 3(\mathrm{p}=0,037)$, mostrando que a presença da informação do país de origem e o selo de DO conferiram uma avaliação significante superior quando comparada ao grupo que não recebeu essas informações. Quanto aos brasileiros, verificou-se diferença estatisticamente significante entre os grupos G5 e G6 ( $p=0,009)$, cujas médias foram de 
4,90 e 5,65. Tal resultado indica que a presença do selo de DO melhorou significantemente a avaliação de qualidade percebida pelos participantes brasileiros.

Em relação à "confiança (ou confiança percebida)", os grupos de ambos os países, em que os respondentes observaram as embalagens acrescentadas do selo de DO (grupos G3 e G6), foram os que alcançaram as maiores médias. A pior média geral atingida, por sua vez, apresentou-se no grupo G1, composto pelos participantes franceses que visualizaram a embalagem sem qualquer selo pelos franceses (G1, média=4,59).

Na comparação de médias entre os grupos compostos por franceses, observou-se uma diferença significante entre os grupos G1 e G2 ( $p=0,048)$ e também entre os grupos $\mathrm{G} 1$ e $\mathrm{G} 3$ ( $p=0,003)$, cujas médias apresentam a maior diferença. No que tange aos grupos dos brasileiros, verificou-se diferença significante apenas entre os grupos G5 e G6 ( $p=0,027)$. Nos dois casos foi evidenciada que a presença do selo de DO proporcionou um aumento significante na percepção e confiança dos respondentes em relação ao produto.

O terceiro construto abordado foi a "intenção de compra", cuja média geral foi de 4,55. Esta média foi a pior alcançada entre os construtos estudados e, assim como na qualidade e confiança percebidas, a avaliação feita pelos brasileiros foi superior à dos franceses. Além disso, a embalagem que resultou nas melhores avaliações entre os franceses, a qual possuía a marca fictícia acrescentada do selo "Made in Brazil" (G2), foi a pior pontuada entre os brasileiros (G5).

A pior média obtida no construto concentrou-se no grupo G1, já a melhor foi do grupo G6. Para tanto, salienta-se a considerável diferença de média entre estes dois grupos, no qual o G1 totalizou 3,85 e o G6, 5,25. Esta diferença, de 1,4 pontos, foi a maior contabilizada entre os construtos abordados na pesquisa. Por meio da ANOVA, foi encontrada diferença significante entre as médias dos grupos $\mathrm{G} 1$ e $\mathrm{G} 2$ ( $p=0,038)$, grupos $\mathrm{G} 1$ e $\mathrm{G} 3(\mathrm{p}=0,048)$ e entre os grupos G5 e G6 ( $p=0,021)$, mostrando que a informação do "Brasil" como país de origem atuou sobre a intenção de compra apenas para o grupo dos franceses. Por outro lado, o selo de DO gerou diferenças significantes na intenção de compra dos participantes das duas nacionalidades.

Sobre a disposição do preço a pagar, as médias gerais se encontram abaixo do preço informado na questão (€5,30 e $R \$ 12,65)$. O grupo $G 2$ foi o que apresentou o valor mais alto dentre os franceses, $€ 5,21$. Já no Grupo do Brasil, o valor médio mais alto foi de $\mathrm{R} \$ 10,59$, apresentado pelo grupo G6. O valor médio mais baixo informado pelos franceses foi referente a embalagem que continha apenas a marca fictícia, visualizada pelo grupo G1. Já para os brasileiros, o produto com o selo "Made in Brazil", observado pelos respondentes do grupo G5, foi o que apresentou a menor média.

Os valores encontrados foram submetidos à análise de variância, que mostrou diferenças significantes de médias entre os grupos dos franceses. Constatou-se que a maior diferença entre as médias se encontra entre os grupos G1 e G2, sendo de -0,82, com p =0,012. Além disso, o grupo G1 apresenta diferença estatisticamente significante também em comparação ao grupo G3, contando com uma diferença de médias de -0,70 e valor de 
$p=0,034$. Referente às respostas dos grupos que contemplavam brasileiros (G4, G5 e G6), não se observaram diferenças de média significantes entre tais grupos.

\section{Discussão dos Resultados}

O estudo teve como objetivo analisar o efeito dos selos "Made in Brazil" e de DO do Cerrado Mineiro Brasileiro em embalagens de café em grãos, tanto em mercado nacional quanto francês. Dessa forma, os resultados obtidos indicam que a adição do selo "Made in Brazil" na embalagem do café apresentado não conferiu diferença significante na percepção de qualidade dos respondentes franceses. Conclui-se que o fato do café brasileiro ser vastamente conhecido, a adição do selo não necessariamente lhe proporciona a percepção de um maior nível de qualidade. Isso permite presumir, então, que o consumidor francês não necessariamente associa melhor qualidade de um produto à nacionalidade brasileira, mas sim aos selos de qualidade $e$ autenticidade do produto, já que a embalagem com o selo de denominação de origem promoveu um aumento significante na percepção de qualidade, quando comparado ao grupo de controle.

O selo de DO apresentou resultado significantemente superior na percepção de qualidade do consumidor brasileiro do grupo G6 em relação ao grupo G5, comprovando que, ao acrescentar à embalagem de marcas de café o selo de DO, houve um aumento da percepção de qualidade. Isso evidencia que o reconhecimento da região mineira como grande produtora de café é relevante. É oportuno destacar que o selo de DO apenas pode conferir diferenciação caso seja reconhecido pelos potenciais consumidores (Alavoine-Mornas, 1997).

No que diz respeito à confiança, conforme diferença significante encontrada entre os grupos G1 e G2, observou-se um efeito positivo da informação do país de origem Brasil entre os consumidores franceses. A sua explicação pode estar relacionada ao seu grande reconhecimento global, que não confere uma maior qualidade aos seus produtos, mas pode garantir credibilidade e tradição no mercado mundial. Além disso, notou-se também uma diferença significante entre os grupos G1 e G3, mostrando que ao adicionar em embalagens de café o selo "Made in Brazil" e o selo de DO, ocorreu um aumento significante da confiança percebida pelos franceses. Tal situação pode ser explicada pelas diversas características do selo de DO, que além de conferir autenticidade e regionalidade, demonstra inspeção e monitoramento dos produtos e de seus métodos de elaboração.

Ao incorporar o selo de DO na embalagem, os respondentes brasileiros se mostraram mais confiantes (confiança percebida) em relação ao produto, contrariando o que disse Calliari et al. (2007). Naquela época, segundo o autor, as certificações no Brasil ainda se encontravam em fase de expansão e aprimoramento, não sendo de conhecimento do público geral consumidor. Atualmente, porém, os resultados do estudo apontam em uma direção contrária, evidenciando um maior conhecimento do público consumidor sobre a região do Cerrado Mineiro como uma das principais regiões reconhecidas na produção de café. 
Acerca da utilização dos selos "Made in Brazil" e de DO como forma de aumentar a intenção de compra, verificou-se um aumento significante na intenção de compra dos franceses gerado pelo "Made in Brazil" e pelo selo de DO. Para os respondentes brasileiros, ainda que a informação da origem nacional não tenha produzido diferenças na intenção de compra, o selo de DO do Cerrado Mineiro foi capaz de promover um aumento significante na avaliação deste construto, corroborando com os achados de Lorenz, Hartmann e Simons (2015).

Porém, a intenção de compra foi o construto do estudo que apresentou as médias mais baixas, tanto para brasileiros quanto franceses. É possível justificar tal resultado através do público escolhido para a presente pesquisa, o qual, em sua grande parte, foi formado por estudantes de até 30 anos de idade. Por mais que os respondentes possam ter identificado valor no café apresentado, os mesmos não manifestaram variações na intenção de comprá-lo, possivelmente por não possuírem o hábito ou interesse na aquisição deste tipo de produto, especialmente no contexto de supermercado (situação sugerida no experimento).

Na avaliação da disposição de preço a pagar, na presença da informação do país de origem e do selo de DO, foi observado um aumento significante apenas para os respondentes franceses. No que diz respeito aos brasileiros, tanto o selo de DO quanto a informação do país de origem não surtiram efeitos significantes sobre a disposição de preço a pagar do consumidor. Neste caso, o estudo de Mascarenhas e Wilkinson (2014) vem ao encontro dos resultados, evidenciando que nos mercados em desenvolvimento, grande parte do público consumidor não possui conhecimento a respeito das indicações geográficas, impossibilitando que estes verifiquem um maior valor percebido nestes produtos. Somando à situação de ascensão econômica dos mesmos, os consumidores não estarão dispostos a pagar a mais por um produto desconhecido.

Por fim, destaca-se que o selo de DO atuou de forma positiva sobre as percepções dos consumidores, promovendo melhores avalições em todos os construtos, excetuando-se apenas a disposição de preço a pagar para os respondentes brasileiros. Com base nisso, entende-se que os selos de DO se tornam mais eficazes depois da primeira compra (Van Ittersum, 2001). Por isso, orienta-se que os produtores brasileiros de café insistam na utilização do mesmo, pois quanto mais os consumidores experimentarem estes produtos, mais rapidamente será popularizada a região produtora, aumentando a eficácia do selo junto aos consumidores.

\section{Considerações Finais}

Como principal implicação teórico-empírica, o estudo apresentou um avanço na compreensão dos efeitos gerados pelos selos de DO e do efeito país de origem na percepção de consumidores nacionais e internacionais (neste caso, franceses). Foi possível observar as percepções de brasileiros e franceses aos diferentes atributos expostos nas embalagens de um produto, como a informação sobre o país de origem e o selo de DO. Também permitiu constatar que os respondentes franceses reconhecem o Brasil como grande 
produtor cafeeiro, já que a presença do "Made in Brazil" na embalagem levou a avaliações mais positivas na qualidade, na confiança, na intenção de compra e na disposição de preço a pagar. Além disso, também valorizam a presença do selo de DO do Cerrado Mineiro.

Não se pode concluir, no entanto, que os respondentes franceses reconheçam a região em si, mas sim que reconheçam a presença e a relevância do selo. Sendo assim, para se obter resultados mais relevantes com o público francês, são necessários maiores estímulos publicitários a respeito da existência da região do Cerrado Mineiro e da sua tradição como produtora cafeeira. Desse modo, ao observar o selo de DO, o consumidor francês associe-o à tradição da região em produzir cafés autênticos, reconhecendo a validade do selo e elevando a percepção de qualidade do produto.

Os brasileiros parecem conceder importância ao selo de DO, especialmente ao se observar que diferente do que ocorreu com os franceses, o "Made in Brasil" não conferiu melhorias nas avaliações dos consumidores. Porém, a presença do selo de DO de origem levou a um aumento significante nas médias das avalições relacionadas à qualidade, confiança e intenção de compra. Pode-se presumir, com isso, que os respondentes brasileiros reconhecem o Cerrado Mineiro como uma região diferenciada na produção de café, já que é a única a possuir a DO em território nacional.

Como toda pesquisa científica, o presente estudo apresentou limitações, as quais podem exercer influência em futuros estudos a respeito do selo de DO e efeito país de origem. Primeiramente, destaca-se a imagem da embalagem desenvolvida para esse estudo. Nesse caso, a escolha das cores, da tipologia da fonte, aspalavras utilizadas e suas disposições, bem como a imagem do morro presente na embalagem podem ter influenciado as respostas dos participantes do estudo. Ainda que todos os grupos tenham recebido embalagens cuja única diferença residia na presença da informação da origem e do selo de DO, sabe-se que outros atributos extrínsecos relacionados à embalagem também influenciam a percepção e comportamento dos consumidores. Esse fato não foi investigado nessa pesquisa e, frente a isso, pode suscitar estudos futuros.

Outro aspecto limitador refere-se ao público do estudo, que é formado em grande parte por jovens universitários de até 30 anos. Todos os entrevistados declararam consumir a bebida, entretanto, este consumo pode ocorrer através de cafeterias, cafés em cápsulas e solúveis. Sugere-se, como forma de contribuição a esse estudo, a avaliação das percepções de consumidores acima de 35 anos com relação ao café torrado e moído, e também a análise de outras formas de consumo de café.

Ainda que respeitadas as nacionalidades que fazem parteda pesquisa (brasileira e francesa), o estudo não atentou para a investigação das regiões de origem dos respondentes, o que teria permitido melhor compreensão do comportamento de consumo dos mesmos. Nesse sentido, estudos futuros podem investigar esse fato e estabelecer comparativos entre os resultados observados em diferentes regiões de um mesmo país. Ademais, novos estudos podem replicar esta pesquisa com respondentes de outros países, ampliando o número de casos coletados e possibilitando novas e mais robustas comparações. 
Outra limitação do estudo diz respeito à metodologia utilizada, tendo em vista que, conforme Agrawal e Kamakura (1999), a pesquisa, por meio de experimentos, pode não transmitir a real experiência de compra, uma vez que a situação é hipotética e o respondente não avalia todas as variáveis como comumente faria, o que poderia estimular a realização de experimentos de campo, com consumidores em situações de consumo reais (Gneezy, 2017). Por fim, sugere-se ainda estudos que abordem a comparação do efeito das formas de Indicações Geográficas, Indicação de Procedência e a Denominação de Origem em outros produtos agroalimentares ou em produtos manufaturados.

\section{Referências}

Agrawal, J., \& Kamakura, W. A. (1999). Country of origin: a competitive advantage? International Journal of Research in Marketing, 16(4), 255-267.

Ahmed, S. A., \& D'astous, A. (2008). Antecedents, moderators, and dimensions of country-of-origin evaluations. International Marketing Review, 25(1), 75-106.

Akdeniz Ar, A., \& Kara, A. (2014). Emerging market consumers' country of production image, trust and quality perceptions of global brands made-in China. Journal of Product \& Brand Management, 23(7), 491-503.

Alavoine-Mornas, F. (1997). Fruit and vegetables of typical local areas: consumers' perception and valorization strategies through distributors and producers. Proceedings of 52nd EAAE Seminar, Parma, Emilia-Romanha, Itália.

Almeida, F. C., \& Drouvot, H. (2009). O efeito do país de origem de produtos na percepção de executivos franceses e brasileiros. Gestão \& Regionalidade, 25(73), 48-68.

Andéhn, M., \& Decosta, P. L. E. (2016). The variable nature of country-to-brand association and its impact on the strength of the country-of-origin effect. International Marketing Review, 33(6), 851-866.

Anholt, S. (2007). Competitive identity: the new brand management for nations, cities, and regions. Journal of Brand Management, 14(6), 474-475.

Aprile, M. C., Caputo, V., \& Nayga, R. (2012). Consumers' valuation of food quality labels: the case of the European geographic indication and organic farming labels. International Journal of Consumer Studies, 36(2), 158-165.

Baker, M. J., \& Churchill Jr., G. A. (1997). The impact of physically attractive models on advertising evaluations. Journal of Marketing Research, 14(4), 538-555.

Bhakar, S., Bhakar, S., \& Dubey, A. (2015). Analysis of the factors affecting customers' purchase intention? The mediating role of customer knowledge and perceived value. Advances in Social Sciences Research Journal,2(1), 87-101.

Biehal, G. J., \& Sheinin, D. A. (1998). Managing the brand in a corporate advertising environment: a decision-making framework for brand managers. Journal of Advertising, 27(2), 99-110.

Brasil. (2016a). MAPA - Ministério da Agricultura, Pecuária e Abastecimento - MAPA. Café:saiba mais. Recuperado em 16 junho, 2016, de: http://www.agricultura.gov.br/ vegetal/culturas/cafe/saiba-mais 
Brasil. (2016b). MAPA - Ministério da Agricultura, Pecuária e Abastecimento. Indicação geográfica. Recuperado em 14 junho, 2016, dehttp:///agricultura.gov.br/ desenvolvimento- sustentavel/indicacao-geografica.

Calliari, M. A., Buainain, A. M., Carvalho, S. M. P., Chamas, C. I., Salles-Filho, S. L. M., \& Silveira, J. M. F. J. (2007). Proteção às indicações geográficas: a experiência brasileira. Anais do Seminário Latino-Iberoamericano de Gestión Tecnológica. Buenos Aires, BA, Argentina.

Chamorro, A., Rubio, S., \& Miranda, F. J. (2015). The region-of-origin (ROO) effect on purchasing preferences: the case of a multi regional designation of origin. British Food Journal, 117(2), 820-839.

Chaudhuri, A., \& Holbrook, M. B. (2001). The chain of effects from brand trust and brand affect to brand performance: the role of brand loyalty. Journal of Marketing, 65(2), 81-93.

Chéron, E. J., \& Propeck, J. (1997). The effects of the country of origin on the evaluation of products: a state of the art review and research propositions. Quebec: Centre de Recherche en Gestion, Universidade de Quebec.

Clipa, C. I., Danilet, M., \& Clipa, A. M. (2017). Country of origin effect and perception of romanian consumers. Junior Scientific Researcher Journal, 3(1), 19-29.

Dobrenova, F. V., Grabner-Krauter, S., \& Terlutter, R. (2015). Country-of-origin (COO) effects in the promotion of functional ingredients and functional foods. European Management Journal, 33, 314-321.

Federação dos Cafeicultores do Cerrado. (2015). A federação e seu papel. Recuperado em 3 julho, 2016, de http://www.cerradomineiro.org/index.php?pg=regiao\#group5

Fernández-Ferrín, P., \& Bande-Vilela, B. (2013). Regional ethnocentrism: antecedents, consequencesandmoderatingeffects. Food Quality and Preference, 30(2), 299-308.

Fotopoulos, C., \& Krystallis, A. (2003). Quality labels as a marketing advantage: the case of the "Pdo Zagora" apples in the Greek market. European Journal of Marketing, 37(10), 1350-1374.

García-Gallego, J. M., Chamorro-Mera, A., \& García-Galán, M. D. M. (2015). The region-of-origin effect in the purchase of wine: The moderating role of familiarity. Spanish Journal of Agricultural Research, 13(3), 1-11.

Giraldi, J. M. E., \& Carvalho, D. T. (2004). O uso da informação sobre o país de origem de produtos brasileiros como fonte de vantagem competitiva nos mercados externos. RAM -Revista de Administração Mackenzie, 6(1), 129-156.

Giraldi, J. M. E., Ikeda, A. A., \& Carvalho, D. T. (2008). Atitudes em relação a produtos brasileiros: uma investigação com estudantes holandeses. RAM - Revista de Administração Mackenzie, 9(3), 11-37.

Gneezy, A. (2017). Field experimentation in marketing research. Journal of Marketing Research, 54(1), 140-143.

Gómez, M., \& Molina, A. (2012). Wine tourism in Spain: denomination of origin effects on brand equity. International Journal of Tourism Research, 14(4), 353-368.

Guina, F. T. C., \& Giraldi, J. M. E. (2013). The evaluation of Brazilian beef in Europe: consumers, importers and exporters perspectives. The International Food and Agribusiness Management Review, 16(4), 101-122. 
Gurgel, V. A. (2005). Aspectos jurídicos da indicação geográfica. In: Lages, V., Lagares, L., \& Braga, C. (org.). Valorização de produtos com diferencial de qualidade e identidade indicações geográficas e certificações para competitividade nos negócios. Brasília: SEBRAE, 2005.

Hair Jr., J. F., Black, W. C., Babin, B. J., \& Anderson, R. E. (2010). Multivariate data analysis: a global perspective. New York: Pearson/Prentice Hall.

Ha-Brookshire, J., \& Yoon, S. H. (2012). Country of origin factors influencing US consumers' perceived price for multinational products. Journal of Consumer Marketing, 29(6), 445-454.

Hanzaee, K. H., \& Khosrozadeh, S. (2011). The effect of the country-of-origin image, product knowledge and product involvement on information search and purchase intention. Middle-East Journal of Scientific Research, 8(3), 625-636.

Hauser, M., Jonas, K., \& Riemann, R. (2011). Measuring salient food attitudes and food-related values. An elaborated, conflicting and interdependent system. Appetite, 57(2), 329-338.

Inglehart, R., \& Baker, W. E. (2000). Modernization, cultural change, and the persistence of traditional values. American Sociological Review, 65(1), 19-51.

INPI - Instituto Nacional da Propriedade Industrial. (2015).Indicação geográfica no Brasil. Recuperado em 15 abril, 2016, de http://www.inpi.gov.br/menu-servicos/ indicacao-geografica/indicacao-geografica-no-brasil

Jiménez, N. H., \& San Martín, S. (2010). The role of country-of-origin, ethnocentrism and animosity in promoting consumer trust: the moderating role of familiarity. International Business Review, 19(1), 34-45.

Johansson, J. K. (1989). Determinants and effects of the use of "made in" labels. International Marketing Review, 6(1), 47-58.

Johansson, J. K., \& Nebenzahl, I. D. (1986). Multinational production: effect on brand value. Journal of International Business Studies, 17(3), 101-126.

Kabadayi, S., \& Lerman, D. (2011). Made in China but sold at FAO Schwarz: country-of-origin effect and trusting beliefs. International Marketing Review, 28(1), 102,126, 2011.

Kirk, R. E. (2013). Experimental design: procedures for the behavioral sciences. (4 $4^{\text {th }}$ ed.). Thousand Oaks: Sage Publications.

Khan, J. (2001). Validation in marketing experiments revisited. Journal of Business Research, 64(7), 687-692.

Kohls, V. K., Anjos, F. S., \& Caldas, N. V. (2016). Mutações no mundo vitivinícola: a indicação geográfica como estratégia de qualificação. DRD - Desenvolvimento Regional em Debate, 6(1), 41-62.

Kuznesof, S. Tregear, A., \& Moxey, A. (1997). Regional foods: a consumer perspective. British Food Journal, 99(6), 199-206.

Lampert, S. I., \& Jaffe, E. D. (1998). A dynamic approach to country-of-origin effect. European Journal of Marketing, 32(1/2), 61-78.

Lei n. 9.279, de 14 de maio de 1996 (1996). Dispõe sobre a regulação dos direitos e obrigações relativos à propriedade industrial. Brasília, DF. Recuperado em 10 outubro 2018, de http://www.planalto.gov.br/ccivil_03/Leis/L9279.htm 
Lorenz, B. A., Hartmann, M., \& Simons, J. (2015). Impacts from region-of-origin labeling on consumer product perception and purchasing intention - causal relationships in a TPB based model. Food Quality and Preference, 45,149-157.

Luceri, B., Latusi, S., \& Zerbini, C. (2016). Product versus region of origin: which wins in consumer persuasion? British Food Journal, 118(9), 2.157-2.170.

Maheswaran, D. (1994). Country of origin as a stereotype: effects of consumer expertise and attribute strength on product evaluations. Journal of Consumer Research, 21(2), 354-365.

Maheswaran, D. (2006). Country of origin effects: consumer perceptions of Japan in South East Asia. New York: The Leonard N. Stern School of Business / New York University.

Malhotra, N. K. (2012). Pesquisa de marketing:uma orientação aplicada. (6a. ed.). Porto Alegre: Bookman.

Manrai, L. A., \& Manrai, A. K. (1993). Positioning European countries as brands in a perceptual map: an empirical study of determinants of consumer perceptions and preferences. Journal of Euromarketing, 2(3), 101-129.

Mascarenhas, G., \& Wilkinson, J. (2014). Indicações geográficas em países em desenvolvimento: potencialidades e desafios. Revista de Política Agrícola, 23(2), 103-115.

Mehmet, T., Pirtini, S., \& Erdem, Y.C. (2010). The perceived country of origin images in Turkey. International Business and Economies Research Journal, 9(8), 127-133.

Menapace, L., Colson, G., Grebitus, C., \& Facendola, M. (2011). Consumers' preferences for geographical origin labels: evidence from the Canadian olive oil market. European Review of Agricultural Economics, 38(2), 193-212.

Meyers, L. S., Gamst, G. C., \& Guarino, A. J. (2013). Applied multivariate research: design and interpretation. ( $2^{\text {nd }}$ edition.). Thousand Oaks: Sage Publications.

Nebenzahl, I. D., \& Jaffe, E. D. (1996). Measuring the joint effect of brand and country image in consumer evaluation of global products. International Marketing Review, 13(4), 5-22.

Obermiller, C., \& Spangenberg, E. (1989). Exploring the effects of country of origin labels: an information processing framework. Advances in Consumer Research, 16, 454-459.

Oberthur, T., Laderach, P., Posada, H., Fisher, M. J., Samper, L. F., Illera, J., Collet, L., Moreno, E., Alarcón, R., Villegas, A., Usma, H., Perez, C., \& Jarvis, A. (2011). Regional relationships between inherent coffee quality and growing environment for denomination of origin labels in Nariño and Cauca. Food Policy, 36(6), 783-794.

ONU - Organização das Nações Unidas Brasil. (2015). Commodities representam $60 \%$ das exportações do Brasil, segundo estudo da ONU. Recuperado em 16 maio, 2016, de https://nacoesunidas.org/commodities-representam-60-das-exportacoesdo-brasil-segundo-estudo-da-onu/

Prendergast, G. P., Tsang, A. S. L., \& Chan, C. N. W. (2010). The interactive influence of country of origin of brand and product involvement on purchase intention. Journal of Consumer Marketing, 27(2), 180-188. 
Rambalducci, P. S., Rambalducci, M. J. G., Feitosa, E. S., \& Feitosa, I. L. (2008). Percepção de Universitários Estrangeiros frente à marca Made in Brazil e sua influência na atitude em relação a produtos brasileiros. Anais do III EMA - Encontro de Marketing da Anpad, Curitiba, PR, Brasil.

Remler, D. K., \& Van Ryzin, G. G. (2011). Research methods in practice: strategies for description and causation. Thousand Oaks: Sage Publications.

Shadish, W. E., Campbell, D. T., \& Cook, T. D. (2001). Experimental and quasiexperimental designs for generalized inferences. (2 $2^{\text {nd }}$ edition.). Belmont: Wadsworth/ Cengage Learning.

Souza, E. C., Streblau, S., Silva, D., \& Streblau, V. I. (2014). Imagem do Brasil: similaridades e diferenças na avaliação em dez países. Revista Eletrônica de Negócios Internacionais, 9(2), 59-74.

Steenkamp, J. B. E. M. (1990). ConceLptual model of the quality perception process. Journal of Business Research, 21(4), 309-333.

Sutter, M. B., Polo, E. F., \& Maclennan, M. L. F. (2014). Atributos da imagem do país de origem como fonte de vantagem competitiva: estudo no segmento internacional da moda brasileira. Revista Eletrônica de Negócios Internacionais, 9(2), 75-93

Sweeney, J. C., \& Soutar, G. N. (2001). Consumer perceived value: the development of a multiple item scale. Journal of Retailing, 77(2), 203-220.

Tabachnick, B. G., \& Fidell, L. S. (2012). Using multivariate statistics. (6 $6^{\text {th }}$ edition.). Boston: Pearson.

Van Ittersum, K. (2001). The role of region of origin in consumer decision-making and choice. PhD thesis, Marketing Mansholt Graduate School, Wageningen University, Wageningen, Netherlands.

Verbeke, W., \&Roosen, J. (2009). Market differentiation potential of country-of-origin, quality and traceability labeling. The Estey Centre Journal of International Law and Trade Policy, 10(1), 20.

Verbeke, W., \& Ward, R. W. (2006). Consumer interest in information cues denoting quality, traceability and origin: An application of ordered probit models to beef labels. Food Quality and Preference, 17(6), 453-467.

Warner, R. M. (2013). Applied statistics: from bivariate through multivariate techniques. ( ${ }^{\text {nd }}$ edition.). Thousand Oaks: Sage Publications.

Yeh, C. H., Chen, C. I., \& Sher, P. J. (2010). Investigation on perceived country image of imported food. Food Quality and Preference, 21(7), 849-856.

\section{Agradecimento}

Agradecemos às recomendações dos Avaliadores do presente artigo, as quais contribuíram para a qualificação do nosso trabalho. 
Apêndice A - Imagem da Embalagem Utilizada no Experimento

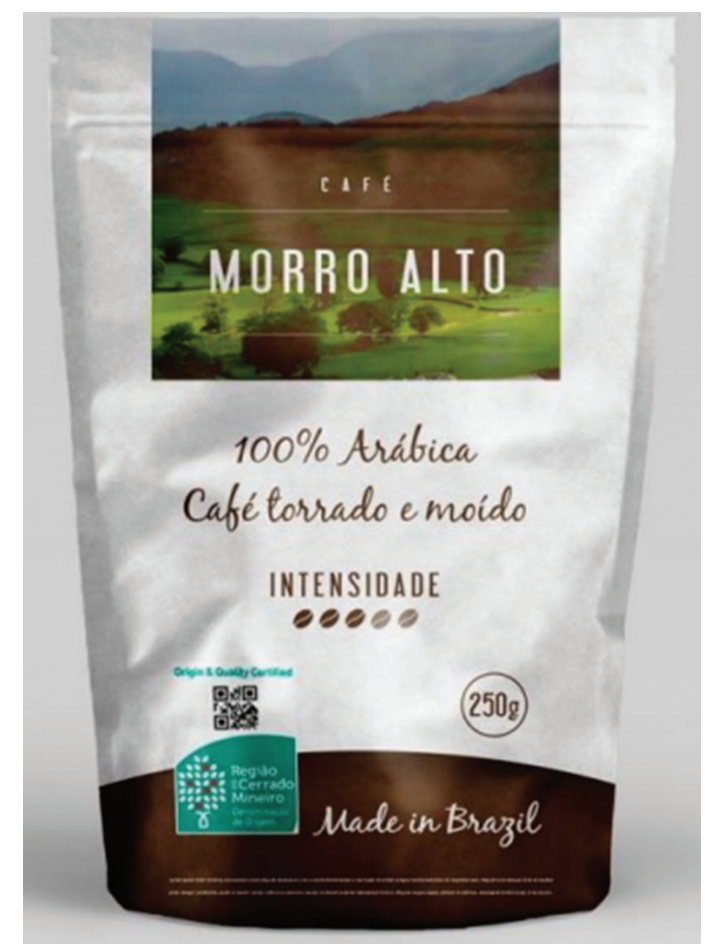

\section{Apêndice B - Construtos e Questões Utilizadas na Pesquisa}

\begin{tabular}{ll}
\hline \multicolumn{1}{c}{ Constutos } & \multicolumn{1}{c}{ Questões Utilizadas na Pesquisa } \\
\hline & 1) Na sua opinião, o produto apresentado na imagem possui uma qualidade consistente? \\
2) Na sua opinião, o produto apresentado na imagem é produzido de maneira apropriada? \\
3) Na sua opinião, o produto apresentado na imagem possui um alto padrão de qualidade? \\
4) Na sua opinião, o produto apresentado na imagem foi produzido por mão de obra desqualificada? \\
5) Na sua opinião, o produto apresentado na imagem possui longa duração de sabor? \\
6) Na sua opinião, o produto apresentado na imagem atenderá as expectativas propostas? \\
7) Você acreditaria no produto apresentado na imagem? \\
8) Na sua opinião, o produto apresentado na imagem é confiável? \\
9) Na sua opinião, o produto apresentado na imagem é honesto? \\
10) Na sua opinião, o produto apresentado na imagem é seguro? \\
11) Você gostaria de experimentar o produto apresentado na imagem? \\
12) Você compraria o produto apresentado na imagem caso o visse em uma loja ou supermercado? \\
13) Você procuraria em uma ou mais lojas, para comprar o produto apresentado na imagem? \\
\hline
\end{tabular}

